\title{
Investigations on Corrosion Inhibitory Effect of Newly Quinoline Derivative on Mild Steel in HCl Solution Complemented with Antibacterial Studies
}

\author{
Ahmed A. Alamiery 1 (D) \\ 1 Department of Chemical and Process Engineering, Faculty of Engineering and Built Environment, University Kebangsaan \\ Malaysia (UKM), P.O. Box: 43000, Bangi, Selangor, Malaysia \\ * Corresponding author email: dr.ahmed1975@ukm.edu.my;
}

Scopus Author ID 42060956400

Received: 29.04.2021; Revised: 28.05.2021; Accepted: 2.06.2021; Published: 9.06.2021

\begin{abstract}
This study analyzed the corrosion inhibitory effects and the antibacterial action of the quinoline derivative, namely N'-(2-hydroxybenzylidene)-2-(quinolin-8-yloxy)acetohydrazide (NHQA). NHQA prevention of corrosion behavior was investigated using weight loss experiments on mild steel coupons in hydrochloric acid. Weight loss tests achieved improved inhibition performance for NHQA, and the high inhibitor efficiency was reached at $303 \mathrm{~K}$, of 93.4 percent at $500 \mathrm{ppm}$ NHQA. Moreover, the effect of immersion time on carbon steel corrosion was investigated using strategies for weight loss. The NHQA mechanism for corrosion inhibition was also examined. These findings confirm that the NHQA molecules can be used in industrial applications as a possible corrosion inhibitor. In an aqueous solution, the synthesized compound (NHQA) can also be used as an antimicrobial agent. The microbial inhibitive efficacy of NHQA against Gram-positive (Staphyloccocus aureus) and Gramnegative bacteria (Escherichia coli, Proteus vulgaris, Klebsiella pneumoniae, and Pseudomonas aeruginosa) was evaluated employee a disc diffusion technique. NHQA has considerable inhibition efficacy toward all investigated bacteria.
\end{abstract}

Keywords: quinoline; NHQA; scavengers; DPPH; antimicrobial; microorganisms.

(C) 2021 by the authors. This article is an open-access article distributed under the terms and conditions of the Creative Commons Attribution (CC BY) license (https://creativecommons.org/licenses/by/4.0/).

\section{Introduction}

Acid corrosion is a universal issue with financial consequences because of the need for mild steel in many sectors, such as petroleum, coal, chemical, and diesel refineries. Corrosion can occur in those industries by chemical washing, beveling, and metal re-scaling [1-3]. Prevention of corrosion is also required in the acidic environment. One of the most effective ways to prevent the degradation of metal is the use of chemical inhibitors. The majority of inhibitors are used to reduce attacks by corrosive ions in the solvent in contact with the metal substrates. Heteroatoms with unsaturated links were typically used as organic inhibitors of mild steel. The efficacy of these synthesized organic inhibitors is linked to the presence of functional groups in their chemical formula, which has heteroatoms such as sulfur, oxygen and nitrogen [4-9]. In several business areas, such as the oil and gas industries, the distribution and disposal of the water, geothermal plants, and many areas of nuclear industry such as waste management and power stations or fuel retreatment units, corrosion from bacteria is a concern $[10,11]$. The effect of biocorrosion is the association between metal surface, abiotic corrosion products, and bacterial cells and their metabolites $[12,13]$, which is also synergistic. In naturally occurring 
biofilms, these bacteria normally coexist to form complex consortiums on corroding metallic surfaces $[14,15]$. Therefore, corrosion inhibitors with antimicrobial impacts on microbial corrosion inductors are important as they minimize equipment and service lines' biological damage [16,17]. Quinoline derivative, namely N'-(2-hydroxybenzylidene)-2-(quinolin-8yloxy)acetohydrazide (NHQA), was synthesized (Figure 1) in this investigation. The NHQA concentration and exposure time assessment were further analyzed on inhibitor performance in 1.0 M hydrochloric acid solution, using mild steel. The antibacterial effects of NHQA were also evaluated. The results were examined in order to assess the possible use of this NHQA as an anti-biocorrosive agent against selected types of Gram-(+) and Gram-(-) bacteria.

\section{Materials and Methods}

\subsection{General.}

All the chemicals used in the current investigation were purchased from Sigma-Aldrich company-Malaysia (analytical grade) and were used directly without further purifying. CHN analysis was conducted on an Erba analyzer 5500 Carlo CHN.

\subsection{Corrosion inhibition techniques.}

The mild steel tested coupons with the chemical composition (weight \%) Iron, Carbon (0.210), Silicon (0.380), Phosphorus (0.090), Manganese (0.050), sulfur (0.050), Aluminum (0. 010), were used for weight loss measurements. The tested coupons have the dimensions $4.5 \mathrm{~cm} \times 2.0 \mathrm{~cm} \times 0.025 \mathrm{~cm}$. The surface of the mild steel samples was physically treated with various emery paper grades before conducted the anti-corrosion experiments $[18,19]$. Acetone has been used to degrease coupons and wash with double purified water and then oven-dried until immersing it into the hydrochloric acid solution. In order to prepare a $1 \mathrm{M} \mathrm{HCl}$ solution, hydrochloric acid 37\% analytical grade was diluted with double distilled water. The tested coupons were polished, dried and weighed in order to utilized for the weight loss measurements. Coupons were immersed in $\mathrm{HCl} 1 \mathrm{M}$ medium in the absence and presence of $100,200,300,400$, and $500 \mathrm{ppm}$ of inhibitor for 1,10 , and $24 \mathrm{hr}$ as immersion time at $303 \mathrm{~K}$ $[20,21]$.

\subsection{Preparation of $N^{\prime}-(2-h y d r o x y b e n z y l i d e n e)-2-(q u i n o l i n-8-y l o x y) a c e t o h y d r a z i d e$.}

An ethanolic solution that has equimolar quantities of 2-quinolin-8yloxyacetohydrazide and 2-hydroxybenzaldehyde was refluxed for $6 \mathrm{~h}$. The hot ethyl alcohol was used to recrystallized the dried precipitate. Yield 77 percentage and the melting point was 133 celsius. Calculated/theoretical $\mathrm{CHN}$ analysis for $\mathrm{C}_{18} \mathrm{H}_{15} \mathrm{~N}_{3} \mathrm{O}_{3}: \mathrm{C} 67.28 / 67.87 \%, \mathrm{H}$ 4.71/4.92\%, N 13.08/13.44\%. After that, the mild steel coupons were removed and rinsed with distilled water, acetone, dried and weighed. The weight loss of tested coupons was evaluated by determining the variation in coupon weights in the absence and presence of the tested inhibitor $1 \mathrm{M} \mathrm{HCl}$ solution [22-24].

\subsection{Antibacterial activity.}

NHQA has been in-vitro tested using disc diffusion techniques for antibacterial efficacy against gram-positive bacteria (Staphylococcus aureus) and gram-negative bacteria (Escherichia coli, Proteus vulgaris, Klebsiella pneumoniae, and Pseudomonas aeruginosa). 
Due to its comfortable, decent and cost-effectiveness, the disc diffusion approach has been used. Dimethylformamide has been used to prepare a range of NHQA concentrations $(100,200$ and $500 \mathrm{ppm}$ ). Dimethylformamide has been used as a regulator for each dilution. For the subculture of bacteria, the nutrient agar was utilized. For the subculture of bacteria, the nutrient agar was used. The normal medicinal drug was chloramphenicol (positive control) and the NHQA was compared. Filter papers (No. 4) brand Whatman, used as disk sterilized and immersed in the desired concentrations of the NHQA were $6 \mathrm{~mm}$ in diameter. The socket disks were mounted individually and incubated for $24 \mathrm{hrs}$ at $37{ }^{\circ} \mathrm{C}$ in Petri-dishes with the chosen forms of bacteria. Average \pm SD was tested for antibacterial efficacy [25-27].

\section{Results and Discussion}

\subsection{Chemistry.}

The compound 2-(quinolin-8-yloxy)acetohydrazide refluxed with 2hydroxybenzaldehyde to synthesis the NHQA, as exhibits in Figure 1. The physical characterization for the synthesized NHQA showed that the chemical structure of the NHQA molecule was expected and demonstrated in Figure 1.

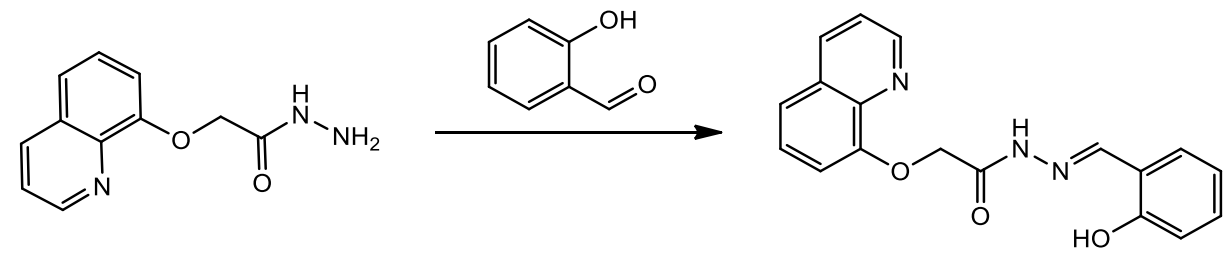

Figure 1. Synthesis of NHQA.

\subsection{Weight loss techniques.}

The weight loss experimental findings for mild steel in $1 \mathrm{M}$ hydrochloric acid solution without and with the addition of the synthesized inhibitor NHQA at $303 \mathrm{~K}$ are demonstrated in Figure 2. The corrosion rate $\left(C_{R}\right.$ in $\left.\mathrm{mg} . \mathrm{cm}^{-2} \cdot \mathrm{h}^{-1}\right)$, inhibition efficiency (IE\%), and surface coverage $(\theta)$ were determined as per in equations (1-3),

$$
\begin{aligned}
& C_{R}=\frac{\Delta W}{a t} \\
& I E(\%)=\frac{C_{R}^{o}-C_{R}}{C_{R}^{o}} \times 100 \\
& \theta=\frac{C_{R}^{o}-C_{R}}{C_{R}^{o}}
\end{aligned}
$$

where $\Delta W$ represent the weight loss average in $\mathrm{mg}, t$ is the exposure time in houres, a is the tested coupon exposure aria in $\mathrm{cm}^{2}$, whereas $C_{R}^{o}$ and $C_{R}$ are the corrosion rates without and with various concentrations of synthesized inhibitors.

The addition of the NHQA as a corrosion inhibitor to the corrosive environment reduces the corrosion rate and increases anticorrosive effectiveness, as demonstrated in Figure 2. The inhibition efficiency increases, whereas the corrosion decrease with increasing the immersion periods from 1 to $10 \mathrm{~h}$. At $24 \mathrm{~h}$, of immersion time, the inhibition efficiency decrease, whereas the corrosion increase [28-31]. 


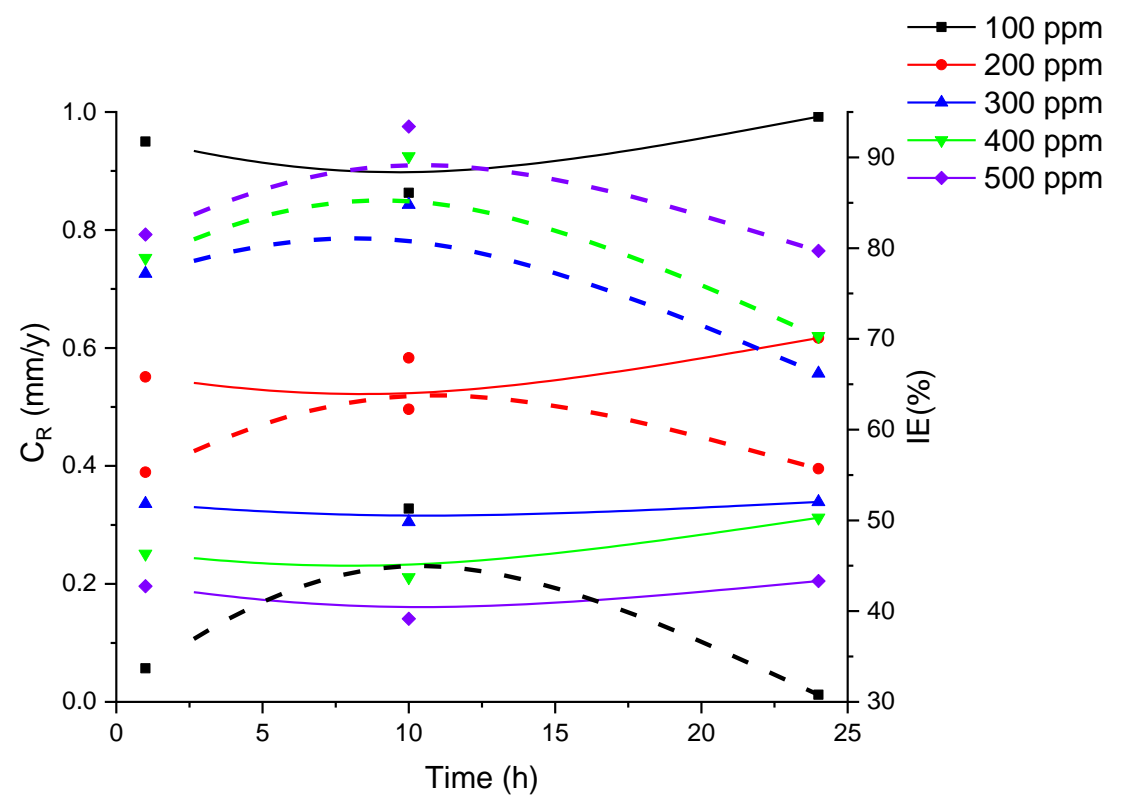

Figure 2. Corrosion rate and inhibition efficiency versus exposure time (1, 5 and $24 \mathrm{~h}$ ) for mild steel in1 $\mathrm{M} \mathrm{HCl}$ solution in the presence of different concentrations (100-500 ppm) of synthesized inhibitor.

These results suggest that the NHQA molecules are efficiently adsorbed on the surface of mild steel. The inhibitive efficacy is increased at higher concentrations, and it exhibits that further NHQA molecules are adsorbed to the mild steel surface. The high value of inhibition efficacy of NHQA is due to the number of oxygen and nitrogen atoms in addition to benzene heterocyclic rings. The inhibitive performance of an organic inhibitor is based on its ability to be adsorbed on a tested steel surface [32]. NHQA molecules inhibited the corrosion rate as a result of the formation of coordination bonds between the NHQA molecules and steel surface through electron pairs of oxygen and nitrogen atoms of NHQA molecules, which coordinate with empty d-orbital of iron atoms on the mild steel surface [33-35].

\subsection{Antibacterial studies.}

Figure 3 shows the effects of the disk diffusion techniques. The tests have been replicated three times, with a default error of $\pm 0.1 \mathrm{~mm}$. The negative control and solvent were dimethyl-formamide for NHQA, used during all the experiments in this investigation. These investigations showed that NHQA has a major effect on the human pathogenic screened bacteria, as seen in Figure 3.

From the experimental results as in Figure 3, it is obvious that the tested compound (NHQA) exhibits considerable efficacy versus G(+) Staphylococcus aureus than the efficiency against $\mathrm{G}(+)$. The inhibition performance increased with an increase in the concentration of NHQA [36-38].

The oxygen and nitrogen atoms, in addition to $\mathrm{C}=\mathrm{N}$ group were correlated with an increased inhibitive efficacy for tested gram-positive bacteria. NHQA also exhibits a good antimicrobial performance against $P$. vulgaris. The antibacterial findings exhibit that the NHQA molecules have significant inhibitive activities against all tested bacteria but are still lower than that for the chloramphenicol (control). 

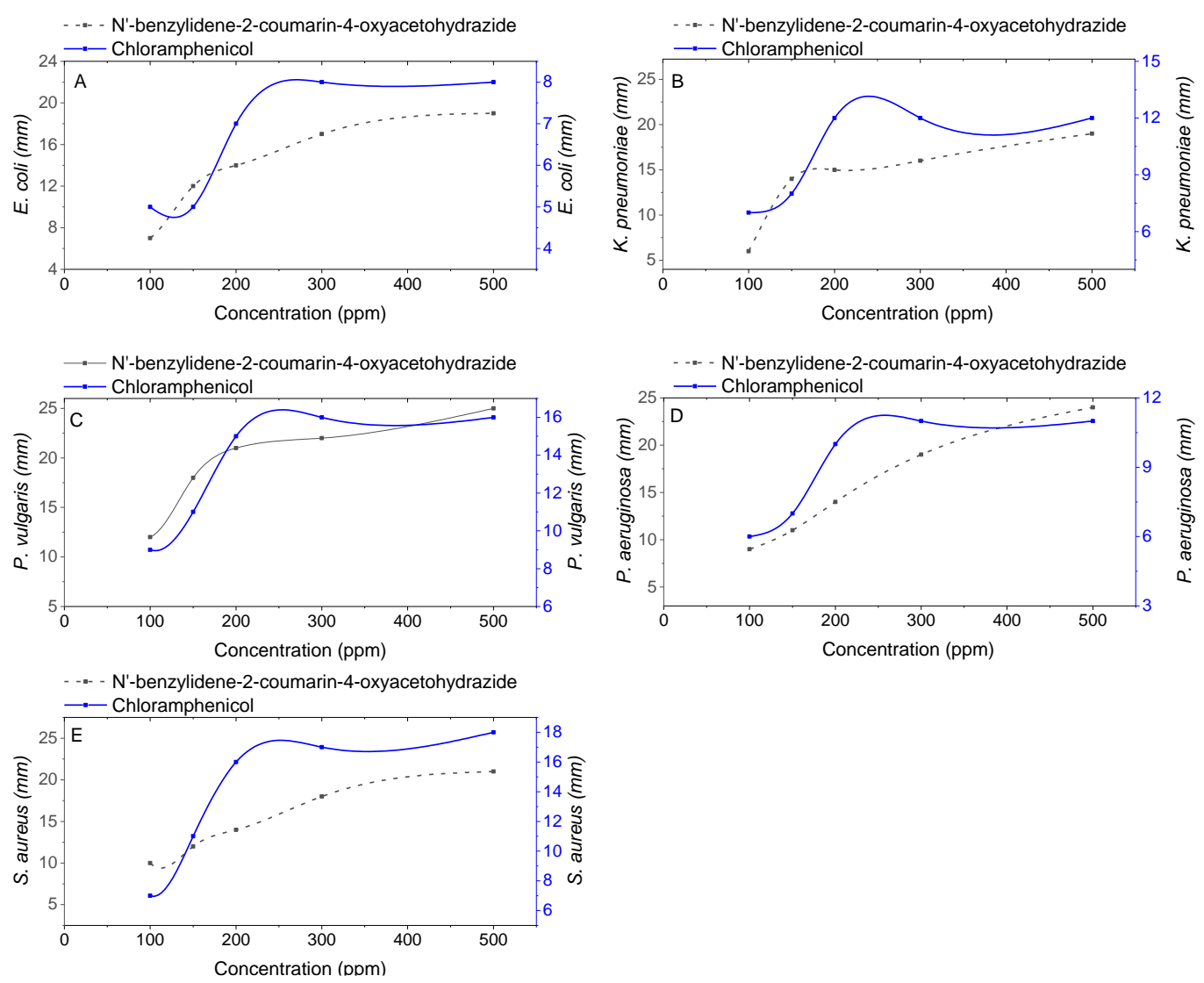

Figure 3. Antibacterial efficiencies of various concentrations of NHQA compare to chloramphenicol.

\section{Conclusions}

In conclusion, N'-(2-hydroxybenzylidene)-2-(quinolin-8-yloxy)acetohydrazide (NHQA). was synthesized by reacting 2-(quinolin-8-yloxy)acetohydrazide refluxed with 2hydroxybenzaldehyde. Weight loss measurements were used to study the inhibitive performance of NHQA as a corrosion inhibitor derived for mild steel in $1 \mathrm{M} \mathrm{HCl}$ solution. Experimental results exhibit that NHQA is an excellent corrosion inhibitor for mild steel surface in $1 \mathrm{M}$ hydrochloric acid media with the highest inhibition activity of $93 . \%$ at $500 \mathrm{ppm}$. The inhibition activity increases with increasing NHQA concentration and decreases with increasing the immersion periods. NHQA was tested against selected kinds of $\mathrm{G}(+)$ (Staphyloccocus aureus) and G(-) (E. coli, Proteus vulgaris, Pseudomonas, and Klebsiella pneumoniae) bacteria as human pathogenic strains. NHQA molecules have important growth inhibition efficacy against all tested human pathogenic strains and are promising to act as a significant antibacterial compound comparing with the reference (chloramphenicol).

\section{Funding}

This research received no external funding.

\section{Acknowledgments}

The authors are grateful to the University Kebangsaan Malaysia (UKM) for support.

\section{Conflicts of Interest}

The authors declare no conflict of interest. 


\section{References}

1. Issa, A.Y.; Rida, K.S.; Salam, A.Q.; Al-Amiery, A.A. Acetamidocoumarin as a based eco-friendly corrosion inhibitor. International Journal of ChemTech Research 2016, 9, 39-47.

2. Al-Amiery, A.A.; Musa, A.Y.; Kadhum, A.A.H.; Mohamad, A.B. The Use of Umbelliferone in the Synthesis of New Heterocyclic Compounds. Molecules 2011, 16, 6833-6843, https://doi.org/10.3390/molecules16086833.

3. Al-Amiery, A.A.; Al-Majedy, Y.K.; Kadhum, A.A.H.; Mohamad, A.B. New Coumarin Derivative as an Eco-Friendly Inhibitor of Corrosion of Mild Steel in Acid Medium. Molecules 2015, 20, 366-383, https://doi.org/10.3390/molecules20010366.

4. Kadhum, A.A.H.; Mohamad, A.B.; Hammed, L.A.; Al-Amiery, A.A.; San, N.H.; Musa, A.Y. Inhibition of Mild Steel Corrosion in Hydrochloric Acid Solution by New Coumarin. Materials 2014, 7, 4335-4348, https://doi.org/10.3390/ma7064335.

5. Kadhim, A.; Al-Amiery, A.; Alazawi, R. Al-Ghezi, M.; Abass, R. Corrosion inhibitors. A review. Int. J. Corros. Scale Inhib. 2021, 10, 54-67, https://doi.org/10.17675/2305-6894-2021-10-1-3.

6. Hanoon, M. Resen, A. M.; Al-Amiery, A. A.; Kadhum, A. A. H.; Takriff, M. S. Theoretical and Experimental Studies on the Corrosion Inhibition Potentials of 2-((6-Methyl-2-Ketoquinolin-3-yl)Methylene) Hydrazinecarbothioamide for Mild Steel in $1 \mathrm{M} \mathrm{HCl}$. Prog. Color Colorants Coat. 2022, 15, 21-33.

7. Hashim, F.G.; Salman, T.A.; Al-Baghdadi, S.B.; Gaaz, T.; Al-Amiery, A.A. Inhibition effect of hydrazinederived coumarin on a mild steel surface in hydrochloric acid. Tribologia 2020, 37, 45-53.

8. Resen, A.M.; Hanoon, M.; Salim, R.D.; Al-Amiery, A.A.; Shaker, L.M.; Kadhum, A.A.H. Gravimetrical, theoretical, and surface morphological investigations of corrosion inhibition effect of 4-(benzoimidazole-2yl) pyridine on mild steel in hydrochloric acid. Koroze a Ochrana Materialu 2020, 64, 122-130, https://doi.org/10.2478/kom-2020-0018.

9. Al-Amiery, A.A.; Shaker, L.M. Corrosion inhibition of mild steel using novel pyridine derivative in $1 \mathrm{M}$ hydrochloric acid. Koroze a Ochrana Materialu 2020, 64, 59-64, https://doi.org/10.2478/kom-2020-0009.

10. Braihi, A.J.; Jawad, A.J.; Kadhum, A.A.H.; Aljibori, H.S.S.; Al-Amiery, A.A. Chemical resistance of N/SB rubber blends for surfaces corrosion protection of metallic tanks in petrochemical industries. Koroze a Ochrana Materialu 2020, 64, 65-71, https://doi.org/10.2478/kom-2020-0010.

11. Mohamad, A.B.; Kadhum, A.A.H.; Al-Amiery, A.A.; Ying, L.C.; Musa, A.Y. Synergistic of a coumarin derivative with potassium iodide on the corrosion inhibition of aluminum alloy in $1.0 \mathrm{M} \mathrm{H} 2 \mathrm{SO}$. Metals and Materials International 2014, 20, 459-467, https://doi.org/10.1007/s12540-014-3008-3.

12. Kadhum, A.A.H.; Mohamad, A.B.; Hammed, L.A.; Al-Amiery, A.A.; San, N.H.; Musa, A.Y. Inhibition of mild steel corrosion in hydrochloric acid solution by new coumarin. Materials 2014, 7, 4335-4348, https://doi.org/10.3390/ma7064335.

13. Salman, T.A. ; Zinad, D.S.; Jaber, S.H.; Al-Ghezi, M.; Mahal, A.; Takriff; Al-Amiery, M.S. Effect of 1,3,4 Thiadiazole Scafold on the Corrosion Inhibition of Mild Steel in Acidic Medium: An Experimental and Computational Study. J. BioTribo-Corrosion 2019, 5, 1, https://doi.org/10.1007/s40735-019-0243-7.

14. Habeeb, H.J.; Luaibi, H.M.; Dakhil, R.M. ; Kadhum, A.A.H.; Al-Amiery, A.; Gaaz, T.S. Development of new corrosion inhibitor tested on mild steel supported by electrochemical study. Results Phys. 2018, 8, 1260, https://doi.org/10.1016/j.rinp.2018.02.015.

15. Al-Amiery, A.; Kadhim, A.; Mohamad, A.;Musa, A.; Li, C. Electrochemical study on newly synthesized chlorocurcumin as an inhibitor for mild steel corrosion in hydrochloric acid. Materials 2013, 6, 5466, https://doi.org/10.3390/ma6125466.

16. Junaedi, S.; Kadhim, A.; Al-Amiery, A.; Mohamad, A.; Takriff, M. Synthesis and characterization of novel corrosion inhibitor derived from oleic acid: 2-Amino5-Oleyl1,3,4-Thiadiazol (AOT). Int. J. Electrochem Sci. 2012, 7, 3543.

17. Jawad, Q. A. Zinad, D. S. Salim, R. D. Al-Amiery, A. Gaaz, T. S. Takriff, M. S.; Kadhum, A. Synthesis, Characterization, and Corrosion Inhibition Potential of Novel Thiosemicarbazone on Mild Steel in Sulfuric Acid Environment. Coatings 2019, 9, 729, https://doi.org/10.3390/coatings9110729.

18. Al-Amiery, A. Antimicrobial and antioxidant activities of new metal complexes derived from (E)-3((5-phenyl-1,3,4-oxadiazol-2-ylimino) methyl)naphthalen-2-ol. Med. Chem. Res. 2012, 21, 3204-3213, https://doi.org/10.1007/s00044-011-9880-1. 
19. Jamil, D.M. Al-Okbi, A.K. Al-Baghdadi, S.B. Al-Amiery, A. Kadhim A.; Gaaz, T.S. Experimental and theoretical studies of Schiff bases as corrosion inhibitors. Chem. Cent. J. 2018, 12, 1, https://doi.org/10.1186/s13065-018-0376-7.

20. Yousif, E. Win, Y. Al-Hamadani, A. Al-Amiery, A. Kadhum, A.; Mohamad, A. Furosemi as an environmental friendly inhibitor of corrosion of zinc metal in acid medium experimental and theoretical studies. Int. J. Electrochem Sci. 2015, 10, 1708.

21. Yamin, J.A.A.; Sheet E.; Al-Amiery, A. Statistical analysis and optimization of the corrosion inhibition efficiency of a locally made corrosion inhibitor under different operating variables using RSM. Int. J. Corros. Scale Inhib. 2020, 9, 502.

22. Al-Majedy, Y.K.; Kadhum, A.A.H.; Al-Amiery, A.A.; Mohamad, A.B. Synthesis and characterization of some new 4-hydroxycoumarin derivatives. Molecules 2014, 19, 11791-11799, https://doi.org/10.3390/molecules190811791.

23. Al-Amiery, A.A.; Kadhum, A.A.H.; Al-Majedy, Y.K.; Ibraheem, H.H.; Al-Temimi, A.A.; Al-Bayati, R.I.; Mohamad, A.B. The legend of 4-aminocoumarin: Use of the Delépine reaction for synthesis of 4iminocoumarin. Research on Chemical Intermediates 2013, 39, 1385-1391, https://doi.org/10.1007/s11164012-0694-7.

24. Al-Amiery, A.A.; Al-Bayati, R.I.H.; Saour, K.Y.; Radi, M.F. Cytotoxicity, antioxidant, and antimicrobial activities of novel 2-quinolone derivatives derived from coumarin. Research on Chemical Intermediates 2012, 38, 559-569, https://doi.org/10.1007/s11164-011-0371-2.

25. Al-Majedy, Y.K.; Kadhum, A.A.H.; Al-Amiery, A.A.; Mohamad, A.B. Coumarins: The antimicrobial agents. Systematic Reviews in Pharmacy 2016, 8, 62-70.

26. Al-Amiery, A.; Ahaker, L.; Gaaz, T. Hydroxycoumarin Grafted with Hydrazine: Synthesis, Structure Elucidation and Assessment of Antioxidant and Antibacterial Characteristics. Biointerface Research in Applied Chemistry 2021, 11, 10393 - 10401, https://doi.org/10.33263/BRIAC113.1039310401.

27. Al-Amiery, A.A.; Kadhum, A.A.H.; Mohamad, A.B. Antifungal activities of new coumarins. Molecules 2012, 17, 5713-5723, https://doi.org/10.3390/molecules17055713.

28. Resen, A.M.; Hanoon, M.M.; Alani, W.K.; Kadhim, A.; Mohammed, A.; Gaaz, T.; Kadhum, A.; Al-Amiery, A.; Takriff, M. Exploration of 8-piperazine-1-ylmethylumbelliferone for application as a corrosion inhibitor for mild steel in hydrochloric acid solution. Int. J. Corros. Scale Inhib. 2021, 10, 368-387.

29. Zinad, D.; Hanoon, M.; Dawood, R.; Ibrahim, S.; Al-Amiery, A.; Takriff, M.; Kadhum, A. A new synthesized coumarin-derived Schiff base as a corrosion inhibitor of mild steel surface in $\mathrm{HCl}$ medium: gravimetric and DFT studies. International Journal of Corrosion and Scale Inhibition 2020, 9, 228-243, https://doi.org/10.17675/2305-6894-2020-9-1-14.

30. Zinad, D.; Jawad, Q.; Mahmood, M.; Mahal, A.; Mohamed, 1.; Al-Amiery, A. Adsorption, temperature and corrosion inhibition studies of a coumarin derivatives corrosion inhibitor for mild steel in acidic medium: gravimetric and theoretical investigations. Int. J. Corros. Scale Inhib. 2020, 9, 134-151, https://doi.org/10.17675/2305-6894-2020-9-1-8.

31. Al-Azawi, K.F.; Al-Baghdadi, S.B.; Mohamed, A.Z.; Al-Amiery, A.A.; Abed, T.K.; Mohammed, S.A.; Kadhum, A.A.H.; Mohamad, A.B. Synthesis, inhibition effects and quantum chemical studies of a novel coumarin derivative on the corrosion of mild steel in a hydrochloric acid solution. Chemistry Central Journal 2016, 10, https://doi.org/10.1186/s13065-016-0170-3.

32. Hanoon, M.; Resen, A.; Shaker, L.; Kadhum, A.; Al-Amiery, A. Corrosion Investigation of Mild Steel in Aqueous Hydrochloric Acid Environment Using N-(Naphthalen-1-yl)-1-(4-Pyridinyl)Methanimine Complemented with Antibacterial Studies. Biointerface Research in Applied Chemistry 2021, 11, 9735 9743, https://doi.org/10.33263/BRIAC112.97359743.

33. Fouda, A.; Tilp, A.; Al-Bonayan, A. Conocarpus Erectus Extract as an Eco-Friendly Corrosion Inhibitor for Aluminum in Hydrochloric Acid Solution. . Biointerface Research in Applied Chemistry 2021, 11, 10325 10340, https://doi.org/10.33263/BRIAC113.1032510340.

34. Hussein, R.; Abou-Krisha, M.; Yousef, T. Theoretical and Experimental Studies of Different Amine Compounds as Corrosion Inhibitors for Aluminum in Hydrochloric Acid. Biointerface Research in Applied Chemistry 2021, 11, 9772 - 9785, https://doi.org/10.33263/BRIAC112.97729785.

35. Fouda, A.; El-Gharkawy, E.; Ramadan, H.; El-Hossiany, A. Corrosion Resistance of Mild Steel in Hydrochloric Acid Solutions by Clinopodium acinos as a Green Inhibitor. Biointerface Research in Applied Chemistry 2021, 11, 9786 - 9803, https://doi.org/10.33263/BRIAC112.97869803. 
36. Al-Amiery, A.; Ahaker, L.; Gaaz, T. Synthesis and Structure Elucidation for N-(2-pheny-4- thiazolidinone3-yl)-2-(coumarin-4-yloxy)acetamide and Assessment Antibacterial Characteristics. Biointerface Research in Applied Chemistry 2021, 11, 11338-11346, https://doi.org/10.33263/BRIAC114.1133811346.

37. Fuochi, V.; Rosato, A.; Emma, R.; Furneri, P.M. Colistin and Kanamycin Together in Association with Coridothymus capitatus to Enhance their Antimicrobial Activity and Fight Multidrug-Resistance Pathogens. Biointerface Research in Applied Chemistry 2021, 11, 8608 - 8625 https://doi.org/10.33263/BRIAC112.86088625.

38. Al-Amiery, A.; Al-Majedy, Y.; Abdulreazak, H.; Abood, H. Synthesis, Characterization, Theoretical Crystal Structure, and Antibacterial Activities of Some Transition Metal Complexes of the Thiosemicarbazone (Z)2-(pyrrolidin-2-ylidene)hydrazinecarbothioamide. Bioinorganic Chemistry and Applications 2011, 2011, https://doi.org/10.1155/2011/483101. 